\title{
What does oversight and delegation mean for the Qualified Person Responsible for Pharmacovigilance?
}

\author{
Brian Edwards $^{1 *}$, W N Richardson ${ }^{2}$ \\ ${ }^{1}$ Principal Consultant, NDA Regulatory Science Ltd \\ ${ }^{2}$ Medical Adviser, NDA Regulatory Science Ltd
}

\begin{abstract}
Received: December 11, 2016; Accepted: December 16, 2016; Published: December 26, 2016
*Corresponding author: Brian Edwards, Principal Consultant, Pharmacovigilance \& Drug Safety, NDA Regulatory Science Ltd, Grove House, Guildford Road, Leatherhead, Surrey, KT22 9DF UK, Tel: +44 (0)1372 860631; Mob: +44(0)7894 586771; Fax: +44 (0)1372 860611; Email: brian.edwards@ndareg.com
\end{abstract}

\begin{abstract}
The EU/EEA Qualified Person Responsible for Pharmacovigilance (QPPV) is personally accountable for the pharmacovigilance quality system of a Marketing Authorization Holder (MAH) in the European Union/European Economic Area (EU/EEA). This has resulted in a long list of tasks, implementation of which requires oversight and delegation. Regardless of how these responsibilities appear in the legislation, what they mean in reality has neither been defined nor have they been agreed within the pharmaceutical sector. Based on our own experience and good business practice, we present a personal view on how a QPPV should implement oversight and approach delegation, which can be applied in practice. Training to fulfill these responsibilities is required as part of the toolkit for the QPPV, and the management of the MAH is obliged by the legislation to provide all necessary support to enable the QPPV to discharge his/ her responsibilities.
\end{abstract}

Keywords: Qualified person for pharmacovigilance; Deputy; Oversight; Delegation

\section{Setting the scene}

The EU/EEA qualified person responsible for pharmacovigilance is the most important defined natural person in the EU pharmaceutical legislation. The extensive role and responsibilities are described in GVP Module I Section I.C.1.3 [1]. However, in spite of the exhaustive GVP guidance very little has been written about, and there is no published consensus on, how this role should be effectively implemented [2,3]. Indeed, with no agreed competency framework, it is debatable exactly what it means to be "qualified". Thus, based on our own experience of providing multiple QPPV services in big and small companies over the last 15 years, we would like to share our opinions about how some aspects of this role might be implemented optimally to maximize the benefit to both Marketing Authorization Holder (MAH) and patients as well as to the interrelationships that must be established within the wider company. Not only is the QPPV a legal and regulatory requirement for the MAH but, we believe, faced with the complexity of the GVP modules, the QPPV role is necessary to enable systems-based thinking to improve efficiency and to streamline decision-making. Ideally, safety and pharmacovigilance should be the QPPV's sole occupation, not an extra task in addition to other functions. The skills required and the roles and responsibilities for the QPPV are so numerous and varied that he/she must delegate many tasks to deputies, managers and other staff working within the organization. The QPPV, however, retains accountability in that he/she must maintain oversight over all delegated tasks and the entire pharmacovigilance system.

\section{What should a QPPV expect from the MAH?}

Compliance with regulatory guidance for the QPPV depends on unhindered cooperation with the MAH's organization, which in turn should visibly promote safety to underpin the QPPV role. The MAH must openly acknowledge the importance of this role for organizational success and ensure the views of the QPPV are listened to and be seen to be taken into account. This may be accomplished by:

- Making the position one of high rank in the organization so the QPPV has the authority to act and remove barriers to change.

- Having regular meetings between the QPPV and the chief executive officer and/or the board of the company with regular presentations to the company's senior management.

- Ensuring that the QPPV function has the resources and organizational support necessary to implement and maintain a compliant pharmacovigilance system

- Backing the QPPV when the going gets tough by demonstrating trust and confidence.

- Training the QPPV to develop the necessary skills in leadership and delegation.

- Providing educational opportunities to the QPPV so he or she can continually seek best practices to improve the efficiency of operation of the pharmacovigilance system.

- Ensuring the QPPV receives regular briefings about 
benefit-risk information, and quality and performance metrics concerning the pharmacovigilance system, as agreed with the QPPV.

In return, the attributes required by the MAH of a QPPV might include:

- Being held in high regard by peers regardless of "rank" as a wise counsel - someone who "walks the walk" and not just "talks the talk." This applies both internally within an organization and externally while networking.

- Possessing knowledge and skills required for effective oversight of a pharmacovigilance system with insight into training needs, corporate culture, root cause analysis, designing corrective actions and organizational learning A QPPV does not need to be a medical graduate but, if not, must have ready access to a medical opinion. Indeed, the key skills go way beyond medical and regulatory knowledge typically associated with pharmacovigilance to include skills around communication, organizational ability and team-working [4].

- Understanding what is required to identify and to correct deficiencies in the system to acceptable standards.

- Accessibility and the ability to put members of the organization at ease so they feel they readily turn to the QPPV for a reasonable and pragmatic opinion or advice without fear of impulsive blame or unjustified adverse criticism.

- Being an individual who promotes action, rather than reaction, such as by setting up of training programs, audit and gap-analyses, and supporting the implementation of improved methodologies.

- Being able to explain requirements regarding relevant safety information for benefit-risk assessment and current stakeholder expectations in pharmacovigilance.

\section{Meaning of oversight}

GVP Module 1 states that the QPPV has oversight over the functioning of the system in all relevant aspects, including its quality system....' However, the term oversight is open to interpretation as there is no definition in legislation or guidance as to what "oversight" means. The meaning is reflected in both the definitions arising from two dictionaries as follows: "Merriam-Webster: watchful and responsible care" and "Oxford English Dictionary: The action of overseeing something". It may help to understand in practical terms what oversight means, if we turn to other areas where oversight is applied such as in government and public services. In these sectors, oversight implies scrutiny of processes and holding to account. From this we have concluded that there are three possible components of "oversight" for the QPPV that need to be discussed in the context of the pharmacovigilance system: monitoring of processes, critically appraising policy and practice and advising on improvement.

\section{Need for change management skills and leadership}

Standards for systems-based thinking and behavior are not well-established in the pharmaceutical industry [4]. Within a pharmaceutical company, the responsibilities of the QPPV impact multiple processes, departments, and professionals who may perceive things differently and may have different motivations and incentives. To be a successful QPPV requires an understanding of systems, behavior change, and culture while identifying the needs of the various stakeholders. This requires leadership skills, which differ from but overlap with those of management. The QPPV may be required to act as a manager in one area where he/she may have line management responsibility, whereas outside this area, the QPPV may need different skills to achieve desired aims for the benefit of the system.

\section{The art of delegation is essential for the QPPV function}

GVP Module 1 states that 'The QPPV may delegate specific tasks, under supervision, to appropriately qualified and trained individuals, for example, acting as safety experts for certain products, provided that the QPPV maintains system oversight and overview of the safety profiles of all products. Such delegation should be documented'. Furthermore, GVP Module II concerning the Pharmacovigilance System Master File states that 'the list of tasks that have been delegated by the qualified person for pharmacovigilance shall also be included in the Annexes (see II.B.4.8.)'[5].

Delegation is inevitable for practical implementation of the QPPV role. Not only could no single individual have the time to directly perform all tasks required of the QPPV, but it is also unrealistic to expect that any one QPPV to have all the necessary skills and expertise. Standard Operating Procedures (SOPs) and related documents are important for capturing the details of delegation. In practice, delegation means empowering someone else and giving them the freedom to act. However, as the QPPV always remains accountable, there needs to be clear understanding about what this implied transfer of authority means. Delegation can be a powerful tool for motivation so how this is done is critical. However what training is available for a QPPV about how to delegate?

\section{There are three main forms of delegation:}

1. Delegation of responsibility. This refers to work that is delegated, i.e. the job, the task and the duty.

2. Delegation of authority. This refers to the power or the right to make and implement decisions to enable this responsibility to come to a successful conclusion.

3. Delegation of accountability. For the QPPV this is not possible as he/she is ultimately accountable for the success or failure of the delegated responsibility for a concerned job or task.

By combining 1 and 2, delegation is likely to be effective. If responsibility is given without authority, then this is not full delegation - one does not go without the other. The instructions for such partial delegation need to be explicit. 
It is important to define and comprehend the essential components of delegation before describing a general process for delegating. For that reason, we have chosen description model referred to as the Tannenbaum and Schmidt Continuum (described in Table 1 below) as we believe this is easy to comprehend. This model in Table 1 shows the levels of delegation which refers to the relationship between the level of freedom to act that a QPPV chooses to give to an individual, and the leve

\section{Table 1: Levels of delegation with corresponding implications}

$$
\text { Level of Delegation }
$$

1. "Wait to be told." or "Do exactly what I say." or "Follow these instructions precisely."

2. "Look into this and tell This means investigation and analysis but me what you come up no recommendation. with. I'll decide."

3. "Give me your recommendation, and the other options with the pros and cons of each. I'll let you know whether you can go ahead."

4. "Decide and let me

This means approval of the decision but know your decision, but the delegate is trusted to judge the relative wait for my go ahead." options.

5. "Decide and let me know your decision, then go ahead unless I say not to."

6. "Decide and take action, This form of delegation saves more time but let me know what while still allowing a quicker reaction you did." to wrong decisions not present in fuller delegation.

7. "Decide and take action. This gives full freedom to act to the You need not check back with me." delegate; a high level of confidenvce is necessary and the QPPV delegating would be expected to assess the quality of the activity according to the final outcome and be free to intervene at any stage should concerns arise.

8. "Decide where action This is the greatest freedom that can needs to be taken and manage the situation accordingly. It's your area of responsibility now." be given to another person or team and normally requires a formal documented change in a person's job role. This gives the delegate responsibility for defining what projects and tasks are necessary for the management of a particular area of responsibility, as well as the task or project, and how it is to be done and how quality is to be measured. This would amount to delegating part of the role of QPPV - not just a task or project. of responsibility retained by the QPPV [6]. This may be of value when categorizing delegated tasks in the Pharmacovigilance System Master File.

As the individual's freedom to act is increased according to the level of delegation, so the QPPV's responsibility decreases. Regardless of different levels of delegated responsibility, accountability remains with the QPPV. However, while a QPPV can delegate as many tasks as possible, which can be effectively carried out by others, the QPPV cannot delegate the control of the system. Thus, effective delegation involves achieving the correct balance between effective controls of work and letting people get on with jobs in the best way they know how.

A QPPV needs to develop skills in diplomacy and negotiation to reach agreement with delegates about what they should be doing and the expectations linked to this responsibility. Depending on where the expertise or competency lies, delegation can occur downwards to juniors or upwards to senior staff, or even laterally to peers. The QPPV should ensure that decisions are explained to them so that the QPPV can understand the criteria on which decision were based so that they are able to explain them to a third party. Whatever the rank of the person within a company to whom the QPPV has delegated a task, no one can reasonably hold an individual responsible for some action to which they have not agreed. As regards motivation, a person would be more likely to be committed to delivering a responsibility if they have been through the process of agreeing to do it and understand its importance. This implies that delegates should be consulted about expectations, such as time-scale, resources, budget even the purpose and the method. Of course, certain responsibilities relevant for the QPPV may have already been agreed implicitly within a person's documented job description or employment contract.

Having allocated the different levels of delegation matching tasks with individuals, we would advise The QPPV should consider the following:

- Once a task is delegated, let the person or team get on with it allowing them to have the authority to achieve it. Where possible, the delegate should be allowed to own it within agreed boundaries.

- Introduce delegation of a new task or activity gradually.

- Review a project on the agreed reporting dates without looking over the delegate's shoulder, so-called 'micromanagement'.

- Ensuring the delegates know how to perform task and are aware of sources of relevant information and knowledge.

- Give help and coach when requested because it is important to support those you have delegated to when they are having difficulties without doing the job for them.

- Recognize that those who the QPPV has delegated to may know a better way of doing something than the QPPV does. This should not stop a QPPV from training said staff in the standards he/she would apply so that expectations are clear. 
- Accept that there may be different ways of approaching a particular task, and that one of the best ways of really learning something is through making mistakes. The QPPV should always respect those mistakes that are not caused by idleness or recklessness and from which that the delegate has visibly learnt.

- When errors of concern arise, the QPPV should support constructive analysis of the cause. The QPPV should resist a superficially response and comment specifically in terms of the actual events or circumstances, which led to the error. The objectives of such an analysis can be summarized as helping to ensure that those to whom the task was delegated understand the problem and feel confident enough to resume and to prevent recurrence.

- Accept only what is agreed finished work although this may be a 'Draft' if that is appropriate. Agree in advance the criteria and standards by which the outcome will be judged the deadlines for completion and internal reporting dates when the QPPV wants information on the progress of a project.

- Give credit when a job has been successfully completed with constructive feedback. Public recognition both reinforces the enjoyment of success with those who have been delegated to carry out a task and sets a standard for other employees.

Delegation is not just a matter of telling someone else what to do. It is primarily about entrusting authority from one person to another. There is a wide range of freedom that can be conferred on this other person. The more experienced and reliable the delegate, the more freedom can be transferred. However, the more critical the task, the more cautious one would be about the extent of freedom on offer. It is important also to ask the other person or team what level of authority they are comfortable with accepting. Involving the delegate in agreeing the level of delegated freedom for any particular responsibility is an essential part of the 'contract' that is made with them.

\section{Deputisation}

\section{A Specific Type of Delegation}

One special role for delegation is the deputy QPPV. A deputy is a person appointed or empowered to act for another. However, there is no reference to deputy in the legislation and no consensus as to what this role might involve. This means the QPPV, in discussion with the MAH, must define what deputisation involves including how many deputies would be appropriate. Referring to other sectors of society, a deputy has the power to do every act, which his principal might do, but a deputy cannot make a deputy. A deputy should always act in the name of his principal. The principal is liable for the deputy's acts, and for neglect of the deputy. One of the oldest and best established deputy roles which is legally enshrined, is that of deputy sheriff who is designated to act on behalf of the sheriff in regard to official business or that of a general deputy who has authority to execute all of the regular duties of the office of sheriff and serves process without any special authority from the sheriff.

\section{Conclusion}

The function of the qualified person responsible for pharmacovigilance is appearing in other pharmacovigilance legislation around the world and it remains to be seen whether these roles will be interpreted and applied similarly to the EU/ EEA QPPV. These new roles accentuates the need for guidance and a dedicated training program which was already well overdue in view of the complexity of interactions within a company for assessment of the benefit-risk of medicinal products throughout their life-cycle, and for taking appropriate action. In addition to understanding EU pharmacovigilance regulations and guidance documents, the QPPV must decide how he/she can best apply key activities such as oversight, leadership and delegation in order to fulfill their obligations within the framework of the organization for which he/she is responsible. Based on our experience, we have provided an easily understandable model for delegation with practical advice about implementation.

\section{References}

1. Guideline on good pharmacovigilance practices (GVP) Module I Pharmacovigilance systems and their quality systems Section I.C.1.3. Role of the qualified person responsible for pharmacovigilance in the EU. EMA/541760/2011. 22 June 2012. Available from: http:// www.ema.europa.eu/docs/en_GB/document_library/Scientific_ guideline/2012/06/WC500129132.pdf (URL accessed December 11th 2016).

2. Brown E.G. The Qualified Person for Pharmacovigilance for Europe: A Compliance and Quality Perspective. Int. J Pharm Med. 2005;19(1):7-14.

3. Krokstad T Edwards B. An aviation perspective of safety in the pharmaceutical sector. Pharmacoepidemiol Drug Saf. 2008;17(7):738-40. doi: $10.1002 /$ pds.1578.

4. Edwards B Furlan G. How to Apply the Human Factor to Periodic Safety Update Reports. Drug Saf. $2010 ; 33(10)$ :811-20. doi: 10.2165/11537620000000000-00000.

5. Guideline on good pharmacovigilance practices (GVP) Module II Pharmacovigilance System Master File. (Rev 1) EMA/816573/2011 Rev 1. $9^{\text {th }}$ April 2013. Available from: http://www.ema.europa.eu/docs/en_GB/ document library/Scientific guideline/2012/06/WC500129133.pdf (URL accessed December11 $\left.11^{\text {th }} 2016\right)$.

6. Tannenbaum, R. Schmidt, W. How to choose a leadership pattern Harvard Business Review 1958; 36(2): 95-101 Available from: http://researchmethodology.net/leadership-continuum-theory-by-tannerbaum-andschmidt/ (URL accessed December $11^{\text {th }}$ 2016) http://www.ema.europa. eu/docs/en_GB/document_library/Scientific_guideline/2012/06/ WC500129132.pdf 